\title{
Editorial
}

\section{El conflicto de intereses}

El quehacer de investigación en ciencias sociales -y específicamente en estudios socio-jurídicos- tiene un amplio espectro de temas, enfoques, dimensiones, debates, teorías y prácticas. Sin embargo, toda esta investigación tiene parámetros comunes en la práctica, en la ética y en la integridad de los investigadores, de las investigaciones y de la publicación de los resultados de dichas investigaciones. Existen serias violaciones a la integridad de estas, que van desde los prejuicios de los investigadores o el conflicto de intereses, hasta el fraude o el plagio.

En esta oportunidad quiero resaltar la importancia de las buenas prácticas en los procesos editoriales de las revistas científicas. Al hablar de buenas prácticas, por lo general los editores y miembros de equipos editoriales asumimos que los autores las conocen y están familiarizados con estas; no obstante, la experiencia nos ha demostrado que no siempre es así y que algunos no se toman el tiempo de leer las políticas de cada revista. En el ámbito que nos compete, el de las publicaciones académicas seriadas, el papel de la ética es de suma importancia, debido a que siempre están latentes las amenazas a la integridad de las investigaciones. Una de estas es el plagio, definido por la RAE como el acto de "copiar en lo sustancial obras ajenas, dándolas como propias". Para poder detectar esta mala práctica, el equipo editorial de Estudios Socio-Jurídicos somete todos los manuscritos recibidos a Turnitin; sin embargo, cabe aclarar que la herramienta no siempre es ciento por ciento exacta y, en algunos casos muy puntuales, no reconoce algunas fuentes.

En veinte años de trayectoria es difícil estar exentos de lidiar con malas prácticas, por lo que la revista ha establecido un protocolo a seguir, que 
tiene en cuenta las normas del debido proceso y defensa. En caso de recibir notificaciones de posible plagio en alguno de nuestros artículos publicados, el equipo editorial corroborará la información de inmediato y establecerá las comunicaciones respectivas, tanto con el afectado principal como con el presunto autor de la mala práctica. Si no recibimos una justificación válida y argumentada, procederemos a bajar el artículo de nuestro portal OJS y comenzaremos la gestión para darlo de baja en las bases de datos e índices en los que la revista está indizada. Este protocolo fue construido con asesoría de la Editorial de la Universidad del Rosario, de la Dirección de Jurídicas, y con lo que establece el COPE.

Por último, en cuanto a acciones legales, es necesario recordar que no son las revistas las titulares de los derechos violados, por lo que le compete a quien le fueron vulnerados sus derechos iniciar las acciones correspondientes. En este sentido, hacemos un llamado a no ser solo investigadores, sino a comprometernos con nuestra labor investigativa y no tomar atajos que puedan hacer daño a la comunidad científica.

Este número, dedicado a las perspectivas en derecho privado, también tiene una sección adicional de tres artículos de investigación con temáticas relacionadas con los estudios socio-jurídicos. En "Sobre el concepto de autonomía relativa en las investigaciones jurídicas nacionales", David Orrego señala que la noción de autonomía relativa plantea varios interrogantes sobre los usos políticos del derecho, por lo que surge la necesidad de reflexionar sobre sus capacidades de emancipación, de perpetuación de la desigualdad y de la exclusión. Por su parte, Marina Medan, Carla Villalta y Valeria Llobet, en su artículo "Entre inercias burocráticas y evaluaciones sobre las familias: adolescentes privados de libertad en Buenos Aires, Argentina", procuran aportar a las discusiones en las que se intersecan asuntos relativos al gobierno poblacional con procesos de reproducción estatal de la desigualdad. El último de este bloque de artículos, "Universalidad y derechos sociales: para una revisión constitucional de las políticas sociales en Argentina", escrito por Horacio Javier Etchichury, analiza el alcance de la noción de universalidad en la titularidad de los derechos sociales contenidos en la Constitución argentina.

El número cierra con una reseña de Property and Social Resilience in Ttimes of Conflict: Land, Custom and Law in East Timor, de Daniel Fitzpatrick, Andrew McWilliam y Susana Barnes, en la que Santiago Zuleta afirma que el libro 
analiza las implicaciones y desafíos del Estado nación en Timor Oriental, al diseñar e implementar marcos jurídicos efectivos con el fin de regular derechos de propiedad en tierras indígenas.

Espero que este nuevo número de la revista Estudios Socio-Jurídicos sea de utilidad para la comunidad académica interesada en este tema. 